\title{
Migração Específica de Antioxidante de Embalagens Plásticas para Alimentos
}

\author{
Leda Coltro \\ Centro de Tecnologia de Embalagem - CETEA, Instituto de Tecnologia de Alimentos - ITAL \\ Marina P. Machado \\ Universidade Estadual de Campinas - UNICAMP
}

\begin{abstract}
Resumo: O uso de aditivos em materiais plásticos é essencial para o processamento e desempenho dos plásticos, uma vez que os aditivos conferem características desejadas aos polímeros. No entanto, há restrições determinadas pela Agência Nacional de Vigilância Sanitária (ANVISA) para as embalagens plásticas de alimentos, as quais devem ser avaliadas por meio de ensaios físicos, realizados por laboratório acreditado, para verificar se os requisitos estabelecidos pela ANVISA são atendidos. Sendo assim, o objetivo desse trabalho foi desenvolver metodologia que permita a avaliação da migração de 3-(3,5-di-terc-butil-4-hidroxifenil) propionato de n-octadecila, antioxidante de nome comercial Irganox 1076, CAS 2082-79-3, presente em embalagens plásticas para contato com alimentos, empregando cromatografia líquida de alta eficiência. Esse estudo também teve como finalidade comprovar se o conteúdo de Irganox 1076 de amostras comerciais de filmes plásticos atende ao requisito de limite de migração específica estabelecido pela ANVISA para este aditivo. Os resultados obtidos indicam que a metodologia utilizada para os simulantes aquoso, ácido e gorduroso é satisfatória e adequada para a análise da migração específica do Irganox 1076, uma vez que todos os parâmetros necessários para a validação do método foram atingidos. As amostras de filme de PEBD e de EVA analisadas atendem ao limite de migração específica do Irganox 1076 para todos os simulantes avaliados.
\end{abstract}

Palavras-chave: Antioxidante, migração específica, embalagem plástica, alimentos, HPLC.

\section{Specific Migration of Antioxidant from Plastic Packages for Food}

Abstract: The use of additives in plastics is essential for the processing and performance of plastic products since the additives enhance the desired characteristics of the polymers. Nevertheless, there are restrictions established by the Brazilian Agency of Sanitary Surveillance (ANVISA) for plastic packages intended to be in contact with foodstuffs which must be submitted to analyses at a proper laboratory in order to check the compliance with the requirements established. Therefore, the objective of this study was to develop a method for determining the migration of n-octadecyl 3-(3,5-ditert-butyl-4-hydroxyphenyl) propionate, antioxidant known commercially as Irganox 1076, CAS 2082-79-3, from plastic packages intended to be in contact with foodstuffs employing high performance liquid chromatography. This study also aims to ensure that commercial plastic package samples are in agreement with the requirement established by ANVISA relative to the specific migration limit for this additive. The results have shown that the methodology used for aqueous, acid and fatty simulants is satisfactory for determining the migration of Irganox 1076 since all parameters needed for the validation of the method were achieved. The LDPE and EVA film samples analyzed are in agreement with the specific migration limit of Irganox 1076 for all simulants evaluated.

Keywords: Antioxidant, specific migration, plastic packaging, food, HPLC.

\section{Introdução}

Plásticos flexíveis são muito utilizados em embalagem de alimentos visando à conservação e proteção dos mesmos. Porém, cada alimento necessita de um tipo de embalagem específica, que proporcione uma série de requisitos de proteção para sua melhor conservação, tais como proteção à luz, barreira à umidade, barreira à gases $\left(\mathrm{O}_{2}, \mathrm{CO}_{2}\right.$ etc. $)$, resistência mecânica, entre outros ${ }^{[1]}$.

Diversos aditivos são adicionados às resinas durante o processo de fabricação das embalagens plásticas, com a finalidade de melhorar as propriedades físicas e químicas dos materiais. Existem diversos tipos de aditivos, tais como antioxidantes, plastificantes, deslizantes, estabilizantes, lubrificantes, absorvedores de UV, antiestáticos etc., que são utilizados para melhorar as características do polímero durante sua produção, processamento e uso. Entretanto, os aditivos utilizados em embalagens plásticas para alimentos não devem interferir nas características do alimento, além de não poderem ser tóxicos e nocivos à saúde humana ${ }^{[2-4]}$.
Todas as poliolefinas contêm pelo menos um antioxidante em sua formulação. No entanto, normalmente são empregadas misturas de antioxidantes primários e secundários devido ao efeito sinérgico obtido por esta combinação. Os antioxidantes primários são doadores de prótons e, assim atuam no início do processo de oxidação, bloqueando as reações em cadeia típicas deste processo de degradação. Podem-se citar os fenóis com impedimento estérico como os principais exemplos de antioxidantes primários. Os antioxidantes secundários são decompositores de hidroperóxidos e atuam em uma etapa intermediária das reações de oxidação, sendo os principais exemplos destes aditivos os organofosfitos e os tioésteres ${ }^{[3,5]}$.

Devido ao tamanho reduzido das moléculas dos aditivos, pode ocorrer um processo indesejável de migração dos aditivos para o alimento acondicionado na embalagem plástica, podendo resultar em alterações de cor, sabor, odor, textura, entre outros. Por isso, a fim de proteger os consumidores, a Agência Nacional de 
Vigilância Sanitária (ANVISA) regulamentou a quantidade máxima e o limite de migração específica (LME) de diversos aditivos para embalagens plásticas para contato com alimentos ${ }^{[6]}$.

A Tabela 1 apresenta alguns exemplos de restrição de uso e limite de migração específica para alguns aditivos estabelecidos pela Resolução RDC $n^{\circ} 17$, de 18 de março de 2008, que dispõe sobre regulamento técnico sobre lista positiva de aditivos para materiais plásticos destinados à elaboração de embalagens e equipamentos em contato com alimentos ${ }^{[6]}$. A diferença nos limites de migração específica dos aditivos decorre do processo de migração, que depende do tamanho da molécula e de sua polaridade, bem como da sua toxicidade ${ }^{[7]}$.

$\mathrm{O}$ aditivo 3-(3,5-di-terc-butil-4-hidroxifenil) propionato de n-octadecila, de nome comercial Irganox 1076, CAS 2082-793 , é um antioxidante adicionado principalmente às poliolefinas e tem como característica impedir ou minimizar o processo de oxidação dos polímeros, geralmente denominado de degradação ou envelhecimento ${ }^{[2,3]}$. A concentração deste antioxidante adicionada aos polímeros é muito baixa, geralmente entre 100 e $1000 \mathrm{mg} \cdot \mathrm{kg}^{-1}$, dependendo da aplicação e das condições de processamento. Os antioxidantes são consumidos durante o processo de degradação dos polímeros e, portanto, a quantidade de antioxidante presente no material sem reagir é um indicador do estado de oxidação desse material, sendo necessários métodos analíticos com limite de detecção bem baixo. O limite de migração específica deste antioxidante é de $6 \mathrm{mg} . \mathrm{kg}^{-1}$ e decorre, entre outros fatores, da dose de ingestão diária permitida que é de $0,1 \mathrm{mg} \cdot \mathrm{kg}^{-1[8]}$.

Diversos métodos têm sido empregados para avaliar a migração específica dos antioxidantes, tais como cromatografia líquida de alta eficiência, cromatografia gasosa, cromatografia de fluído supercrítico, extração líquido-líquido, extração em fase sólida etc., sendo que diversos autores demonstraram que a cromatografia líquida é uma técnica precisa e reprodutível para análises de identificação e quantificação de antioxidantes ${ }^{[9-18]}$.

Dopico-Garcia, López-Vilarino e González-Rodriguez ${ }^{[15]}$ desenvolveram um método analítico para a determinação da migração específica dos antioxidantes BHA, DBP, BHT, Irganox 1010, Ethanox 330, Irgafos 168 e Irganox 1076 para simulantes aquosos (ácido e alcoólico) empregando extração em fase sólida dos antioxidantes com cartucho de sílica $\mathrm{C}_{18}$ e determinação por cromatografia líquida de alta eficiência com detector de arranjo de diodos. De acordo com os autores, a taxa de recuperação (78 a $104 \%$, sendo $78 \%$ para o Irganox 1076) e o desvio padrão relativo (2,0 a 7,7\%, sendo 6,5\% para o Irganox 1076) obtidos com este método apresentou melhores resultados do que estudos anteriores que empregavam extração líquido-líquido (66 a 88\% de recuperação e 3,4 a $13 \%$ de desvio padrão relativo). O limite de quantificação obtido pelo método analítico de extração em fase sólida foi inferior a $0,24 \mathrm{mg} . \mathrm{L}^{-1}$ para os antioxidantes estudados, sendo $0,20 \mathrm{mg} \cdot \mathrm{L}^{-1}$ para o Irganox $1076^{[11,15]}$.

Assim, o objetivo desse trabalho foi desenvolver metodologia para a avaliação da migração específica do Irganox 1076 de embalagens plásticas para contato com alimentos, empregando cromatografia líquida de alta eficiência. Esse estudo também teve como finalidade determinar a migração específica de amostras comerciais de filme de PEBD e de EVA, a fim de comprovar o atendimento ao requisito de LME estabelecido pela ANVISA.

\section{Experimental}

\section{Materiais e reagentes}

Os reagentes isopropanol p.a (Merck, Alemanha), água ultrapurificada (Milli-Q), ácido acético glacial p.a. (Merck, Alemanha), álcool etílico p.a. (Merck, Alemanha), isooctano p.a. (Synth, Brasil), acetonitrila grau HPLC (J.T. Backer, EUA) e álcool etílico grau HPLC (J. T. Backer, EUA) foram utilizados sem purificação prévia.

Os aditivos 3-(3,5-di-terc-butil-4-hidroxifenil) propionato de n-octadecila, de nome comercial Irganox 1076 (CAS 2082-79-3) e 2-(2'-hidroxi-3'-terc-butil-5' -metilfenil)-5-cloro benzotriazol, de nome comercial Tinuvin 326 (CAS 3896-11-5), usado como padrão interno, fornecidos pela Ciba Especialidades Químicas Brasil, foram utilizados conforme recebidos.

Foram avaliadas amostras comerciais de filme plástico de PEBD, com espessura de $180 \mu \mathrm{m}$ e de EVA, com espessura de $170 \mu \mathrm{m}$. Os filmes foram fornecidos pela Petroquímica Triunfo S/A.

\section{Métodos}

Todas as amostras foram analisadas empregando-se um cromatógrafo líquido de alta eficiência Agilent, modelo 1100, com detector de arranjo de diodos, operando nas condições cromatográficas apresentadas na Tabela 2.

\section{Quantificação do Irganox 1076 em filmes plásticos}

A quantificação do Irganox 1076 foi efetuada de acordo com método adaptado da norma ASTM D6953-03 (2009) ${ }^{[19]} .5 \mathrm{~g}$ de filme plástico (EVA e PEBD), previamente triturado, foi submetido ao refluxo, sob agitação, em $50 \mathrm{~mL}$ de isopropanol, por 1 hora. Com os extratos de cada replicata do refluxo foram preparadas quatro soluções para cada filme, com concentração de $50 \mathrm{mg} \cdot \mathrm{kg}^{-1}$ de padrão interno. Alíquotas de $10 \mu \mathrm{L}$ de cada solução foram injetadas no HPLC, em triplicata.

\section{Estudo da migração específica do Irganox 1076}

\section{Validação do método}

A validação do método baseou-se nos critérios estabelecidos pela ANVISA e INMETRO ${ }^{[20,21]}$

\section{- Linearidade}

De acordo com a norma CEN/TS 13130-16(2005) ${ }^{[22]}$, a gravidade específica de todos os simulantes deve ser convencionalmente atribuída ao valor 1. Assim, miligramas de substância liberada por litro de simulante corresponde numericamente a miligramas

Tabela 1. Restrições de uso e limites de migração específica para alguns aditivos ${ }^{[6]}$.

\begin{tabular}{|c|c|c|c|}
\hline Nome químico/nome comercial & Função & CAS & LME (mg.kg-1) \\
\hline 3-(3,5-di-terc-butil-4-hidroxifenil)propionato de n-octadecila (Irganox 1076) & Antioxidante & $2082-79-3$ & 6 \\
\hline Butil-hidroxi-tolueno (BHT) & Antioxidante & $128-37-0$ & 3 \\
\hline 1,6-hexametileno-bis(3(3,5-diterc-butil-4-hidroxifenil) propinamida (Irganox 1098) & Antioxidante & 23128-74-7 & 45 \\
\hline Adipato de di-2-etilhexila (DEHA) & Plastificante & $103-23-1$ & 18 \\
\hline Óleo de soja epoxidado(OSE) & Plastificante e estabilizante térmico & $8013-07-8$ & 60 \\
\hline Ftalato de di-2-etilhexila (DEHP) & Plastificante & $117-81-7$ & 1,5 \\
\hline
\end{tabular}

LME = limite de migração específica 
Tabela 2. Parâmetros experimentais do método proposto para a determinação da migração específica de Irganox 1076.

\begin{tabular}{|c|c|c|}
\hline Parâmetro & $\begin{array}{c}\text { Simulantes aquoso } \\
\text { e ácido }\end{array}$ & $\begin{array}{l}\text { Simulante } \\
\text { gorduroso }\end{array}$ \\
\hline Coluna analítica & \multicolumn{2}{|c|}{$\begin{array}{c}\text { LiChrospher } 100 \text { RP-18E }(250 \mathrm{~mm} \times 4 \mathrm{~mm} \text { d.i., } \\
\text { partículas de } 5 \mu \mathrm{m})\end{array}$} \\
\hline Temperatura & $40^{\circ} \mathrm{C}$ & $25^{\circ} \mathrm{C}$ \\
\hline Fase móvel & $100 \%$ acetonitrila & $\begin{array}{l}95 \% \text { álcool } \\
\text { etílico e } 5 \% \text { água } \\
\text { ultrapurificada }\end{array}$ \\
\hline Fluxo & $2,0 \mathrm{~mL} \cdot \mathrm{min}^{-1}$ & $1,0 \mathrm{~mL} \cdot \mathrm{min}^{-1}$ \\
\hline$\lambda$ de detecção & $200 \mathrm{~nm}$ & $230 \mathrm{~nm}$ \\
\hline Volume de injeção & $10 \mu \mathrm{L}$ & $50 \mu \mathrm{L}$ \\
\hline Tempo de retenção & $12-12,2$ minutos & 8,2 minutos \\
\hline
\end{tabular}

de substância liberada por quilograma de simulante e, portanto, a miligramas de substância liberada por quilograma de alimento.

Assim, soluções estoque de $500 \mathrm{mg} \cdot \mathrm{kg}^{-1}$ foram preparadas pesando-se $50 \mathrm{mg}$ de Irganox 1076 e $50 \mathrm{mg}$ de Tinuvin $326 \mathrm{em}$ balões volumétricos de $100 \mathrm{~mL}$ e completando-se o volume com isopropanol.

Para os simulantes aquoso e ácido, foram preparadas soluções de 2, 4, 6, 8, 10, 15 e 20 mg. $\mathrm{kg}^{-1}$ de Irganox 1076 e 10 mg. $\mathrm{kg}^{-1}$ de Tinuvin 326 transferindo-se alíquotas de 100, 200, 300, 400, 500, 750 e $1000 \mu \mathrm{L}$ da solução estoque de Irganox 1076 e $0,5 \mathrm{~mL}$ da solução estoque de Tinuvin 326 para balões volumétricos de $25 \mathrm{~mL}$ e completando-se o volume com o simulante em estudo (aquoso ou ácido).

Para o simulante gorduroso (isooctano) foram preparadas soluções de 2, 4, 6, 8, 10, 12 e 15 mg.kg-1 de Irganox 1076 transferindo-se alíquotas de 40, 80, 120, 160, 200, 240 e $300 \mu \mathrm{L}$ da solução estoque de Irganox 1076 para balões volumétricos de $10 \mathrm{~mL}$ e completando-se o volume com o simulante. Para este simulante foi utilizada padronização externa.

As injeções no HPLC foram feitas em triplicata.

\section{- Precisão e exatidão}

Foram construídas duas curvas de calibração com pontos de baixa, média e alta concentração do Irganox 1076 em relação ao LME, sendo que cada curva foi obtida por um analista diferente. Para o simulante aquoso, foram injetadas soluções com concentração de 4, 6 e 8 mg. $\mathrm{kg}^{-1}$ de Irganox 1076 e 10 mg. $\mathrm{kg}^{-1}$ de Tinuvins 326. Para o simulante ácido, foram injetadas soluções com concentração de 6 , 8 e 15 mg. $\mathrm{kg}^{-1}$ de Irganox 1076 e 10 mg. $\mathrm{kg}^{-1}$ de Tinuvin 326. Para o simulante gorduroso, foram injetadas soluções com concentração de 6, 8 e 10 mg. $\mathrm{kg}^{-1}$ de Irganox 1076.

A precisão (DPR) e a exatidão (E) foram calculadas de acordo com as Equações 1 e 2:

$$
\begin{aligned}
& \mathrm{DPR}=(\mathrm{DP} / \mathrm{CMD}) \times 100 \\
& \mathrm{E}=\left(\mathrm{C}_{\text {m. exp. }} / \mathrm{C}_{\mathrm{m} \text {. teórica }}\right) \times 100
\end{aligned}
$$

Onde: $D P R$ é o desvio padrão relativo, $D P$ é o desvio padrão, $C M D$ é a concentração média determinada; $E$ é a exatidão, $C_{m \text {. exp }}$ é a concentração média experimental e $C_{m \text {. teórica }}$ é a concentração média teórica.

\section{- Limite de Detecção (LD) e Limite de Quantificação (LQ)}

Para o simulante aquoso, foram construídas três curvas de calibração com as concentrações de 2, 4, 6 e 8 mg. $\mathrm{kg}^{-1}$ de Irganox 1076. Para os simulantes ácido e gorduroso, foram construídas três curvas de calibração com as concentrações de 6, 8, 10 e 15 mg.kg ${ }^{-1}$ de Irganox 1076. Para os simulantes aquoso e ácido foi utilizado Tinuvin 326 como padrão interno na concentração de $10 \mathrm{mg} \cdot \mathrm{kg}^{-1}$.

A partir destas curvas foram calculados os valores de LD e LQ empregando as expressões apresentadas nas Equações 3 e 4:

$$
\begin{aligned}
& \mathrm{LD}=(\mathrm{DP} \times 3) / \mathrm{IC} \\
& \mathrm{LQ}=(\mathrm{DP} \times 10) / \mathrm{IC}
\end{aligned}
$$

onde: DP é o desvio padrão do intercepto com a ordenada, IC é a inclinação da curva de calibração.

Determinação da migração específica de Irganox 1076 de filmes plásticos

Nos ensaios de migração, o contato dos materiais plásticos com os simulantes foi realizado de maneira a reproduzir as condições normais ou previsíveis de elaboração, fracionamento, armazenamento, distribuição, comercialização e consumo dos alimentos. Assim, de acordo com a Resolução RDC n ${ }^{\circ}$ 51, de 26 de novembro de 2010, publicada pela ANVISA no Diário Oficial da República Federativa do Brasil em 22 de dezembro de 2010, para a condição de acondicionamento e uso prolongado a temperaturas de até $40{ }^{\circ} \mathrm{C}$, as condições de tempo e temperatura selecionadas para o ensaio de migração foram 10 dias, a $40{ }^{\circ} \mathrm{C}$, para os simulantes aquoso e ácido e 2 dias, a $20{ }^{\circ} \mathrm{C}$, para o simulante gorduroso (isooctano) $)^{[23]}$.

Para cada simulante foram recortados três corpos-de-prova quadrados, de $5 \mathrm{~cm}$ de lado, de cada amostra de filme e os mesmos foram colocados em contato com os simulantes aquoso e ácido, por 10 dias, a $40{ }^{\circ} \mathrm{C}$, e com o simulante gorduroso por 2 dias, a $20^{\circ} \mathrm{C}$, obedecendo a relação área/volume de $0,6 \mathrm{~cm}^{2} \cdot \mathrm{mL}^{-1[24]}$. Um branco para cada filme também foi preparado e submetido a um mesmo volume de simulante utilizado para o contato com os corpos-deprova e sob as mesmas condições de condicionamento.

Após o tempo de contato, soluções de $10 \mathrm{mg} \cdot \mathrm{kg}^{-1}$ de padrão interno foram preparadas com os simulantes aquoso e ácido que ficaram em contato com as amostras de filmes plásticos. Estas soluções foram injetadas em duplicata. Para o simulante gorduroso, as soluções que ficaram em contato com as amostras de filmes plásticos foram filtradas e injetadas em duplicata.

\section{Resultados e Discussão}

\section{Quantificação do Irganox 1076 em filmes plásticos comerciais de EVA e PEBD}

Segundo informações do fabricante, a amostra comercial de EVA foi formulada com 300 a 600 mg. $\mathrm{kg}^{-1}$ de Irganox 1076 e a amostra comercial de PEBD com 100 a 250 mg. $\mathrm{kg}^{-1}$ de Irganox 1076. As concentrações do aditivo determinadas para as amostras de filme analisadas são apresentadas na Tabela 3.

Como pode ser observado, os valores encontrados para a concentração de aditivo presente nas amostras de filme plástico analisadas é coerente com os valores informados pelo fabricante e confirmam a formulação dos filmes.

\section{Estudo da migração específica do Irganox 1076}

\section{Validação do método}

\section{- Linearidade}

Para avaliação da linearidade do método, as curvas de calibração devem apresentar grandeza semelhante ao limite de migração específica do aditivo estudado (neste caso, $6 \mathrm{mg} \cdot \mathrm{kg}^{-1}$ ) e um mínimo de cinco pontos. 
Assim, para o simulante aquoso a curva de calibração foi construída com concentrações de 2, 4, 6, 8 e 10 mg.kg-1 , obtendo-se uma reta expressa pela Equação 5:

$$
\mathrm{y}=0,1017 \mathrm{x}-0,1309
$$

que apresentou coeficiente de regressão linear de 0,997 .

Tabela 3. Quantificação do Irganox 1076 nas amostras de filme plástico analisadas.

\begin{tabular}{ccc}
\hline \multirow{2}{*}{ Amostra } & \multicolumn{2}{c}{ Concentração $\left(\mathbf{m g . k g}^{-1}\right)$} \\
\cline { 2 - 3 } & EVA & PEBD \\
\hline 1 & 424,9 & 113,5 \\
2 & 421,0 & 111,3 \\
3 & 389,1 & 110,6 \\
4 & 417,9 & 104,7 \\
Média & $413 \pm 16$ & $111 \pm 4$ \\
\hline
\end{tabular}

Para o simulante ácido, a curva de calibração foi construída com concentrações de $6,8,10,15$ e 20 mg. $\mathrm{kg}^{-1}$, obtendo-se uma reta expressa pela Equação 6:

$$
\mathrm{y}=0,1317 \mathrm{x}-0,3598
$$

que apresentou coeficiente de regressão linear de 0,998.

Para o simulante gorduroso, a curva de calibração foi construída com concentrações de 4, 6, 8, 10, 12 e 15 mg. $\mathrm{kg}^{-1}$, obtendo-se uma reta expressa pela Equação 7:

$$
y=6,5098 x-9,9117
$$

que apresentou coeficiente de regressão linear de 0,997.

Portanto, as curvas de calibração para os três simulantes apresentaram coeficientes de correlação superiores a 0,996, estando de acordo com o requisito mínimo estabelecido no guia de validação de métodos da ANVISA ${ }^{[20]}$.

Os picos cromatográficos referentes ao Irganox 1076 na concentração do LME (6 mg. $\left.\mathrm{kg}^{-1}\right)$ para cada simulante são apresentados na Figura 1.

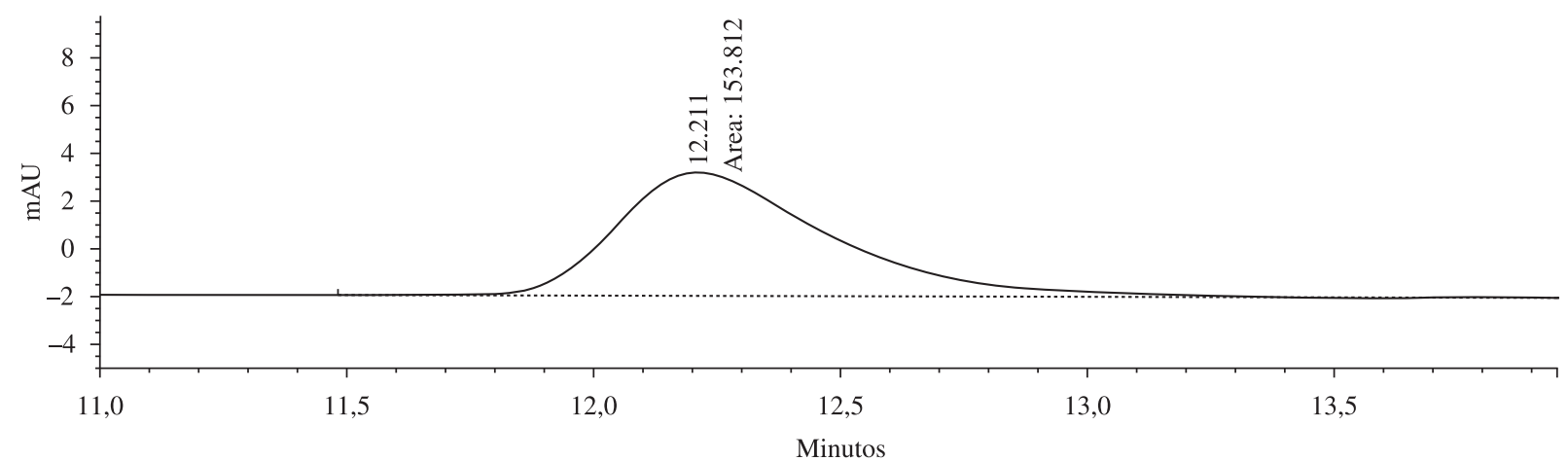

(a)

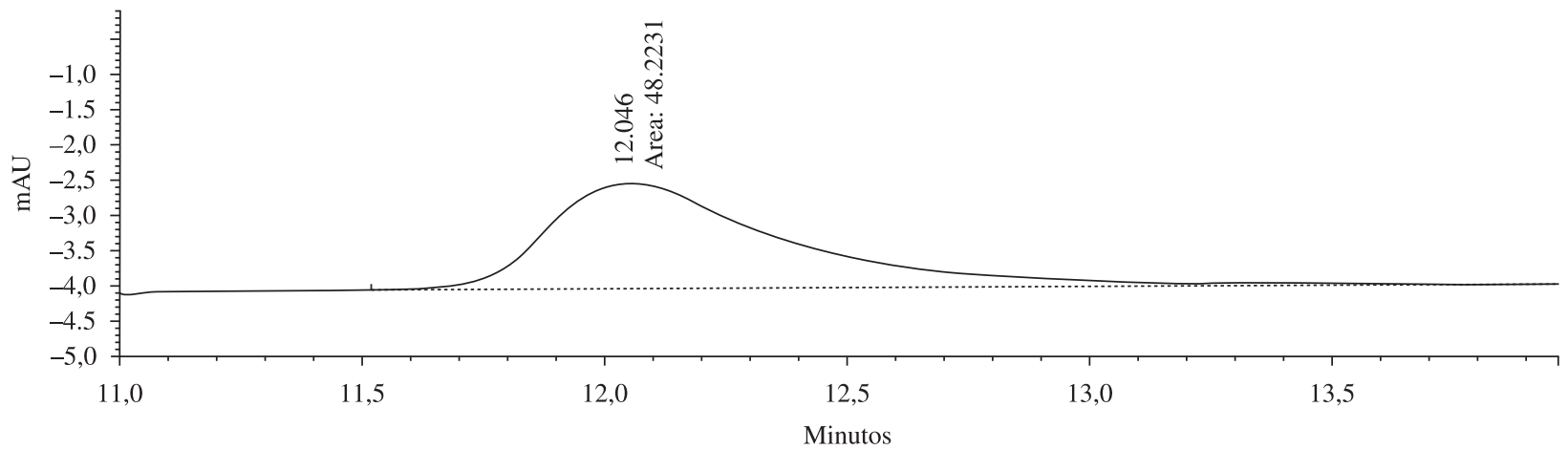

(b)

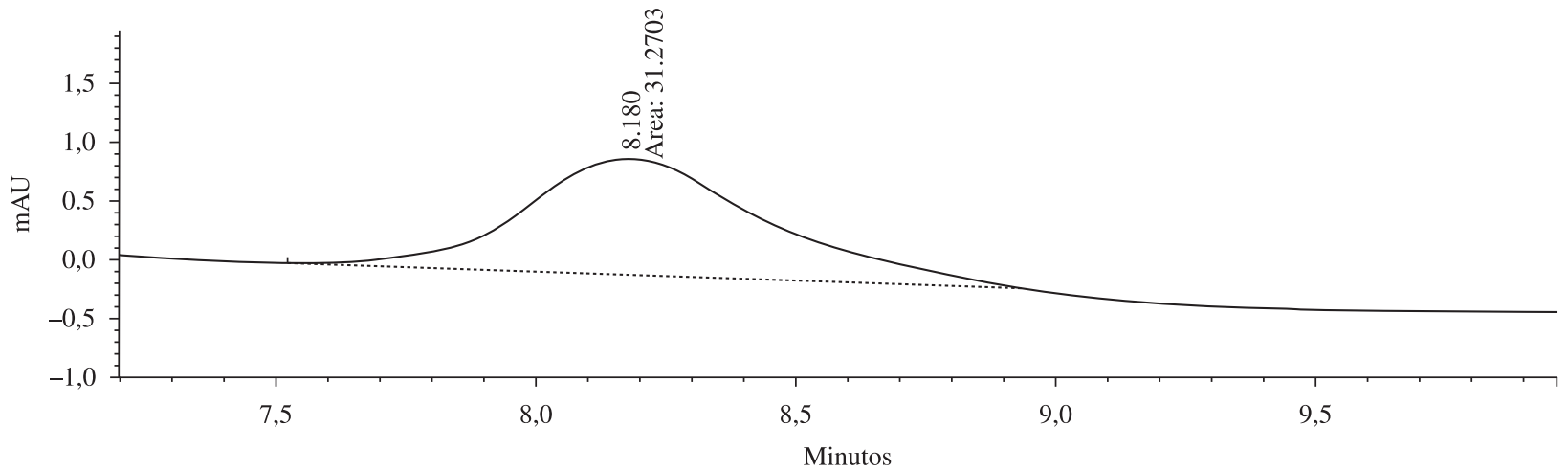

(c)

Figura 1. Cromatogramas referentes a concentração de $6 \mathrm{mg} \cdot \mathrm{kg}^{-1}$ de Irganox 1076 nos diversos simulantes de alimento: a) simulante aquoso, b) simulante ácido, e c) simulante gorduroso (isooctano). 
Como pode ser observado, os picos cromatográficos do Irganox 1076 na concentração de $6 \mathrm{mg} . \mathrm{kg}^{-1}$, apresentaram boa resolução e áreas que permitem a identificação e quantificação do aditivo migrado para os simulantes de alimentos e, portanto, verificação da conformidade das embalagens em relação ao requisito da ANVISA.

- Precisão e exatidão

Soluções de baixa, média e alta concentração de Irganox 1076 em relação ao LME foram injetadas no HPLC, em triplicata, para

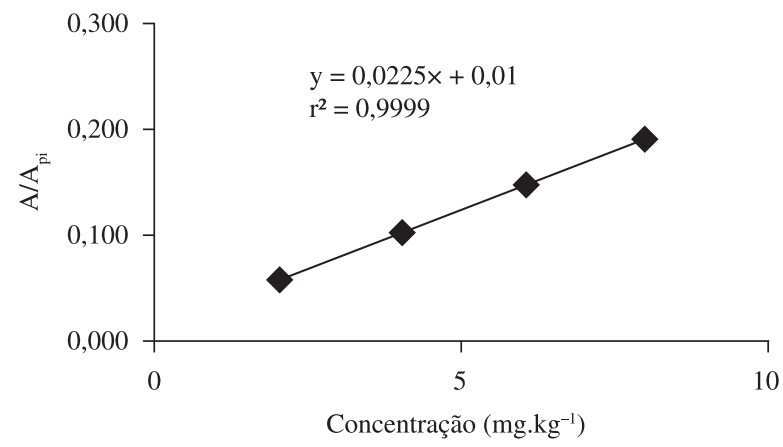

análise da precisão do método. De acordo com o guia de validação de métodos da ANVISA ${ }^{[20]}$, o valor máximo de desvio em relação às triplicatas deve ser de $5 \%$.

Os resultados de precisão intra e intercorrida (repetibilidade e reprodutibilidade) e exatidão (recuperação) obtidos para os três simulantes são apresentados na Tabela 4. Como a variação máxima calculada para a precisão intracorridas foi igual a $4 \%$ e para a precisão intercorridas foi $5 \%$, valores que atendem o requisito da

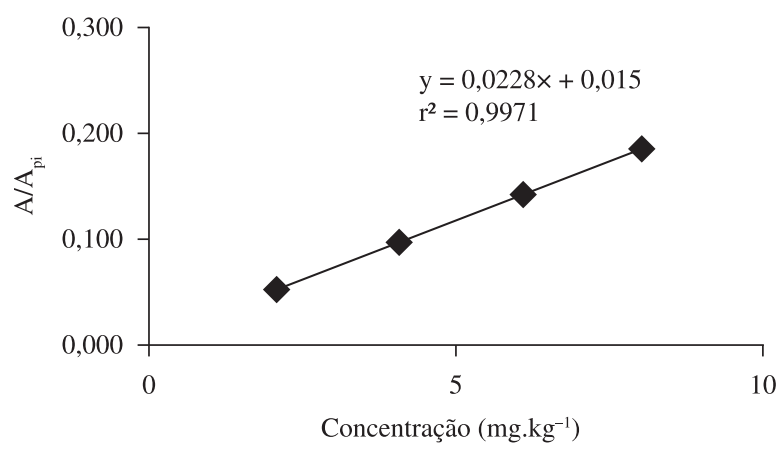

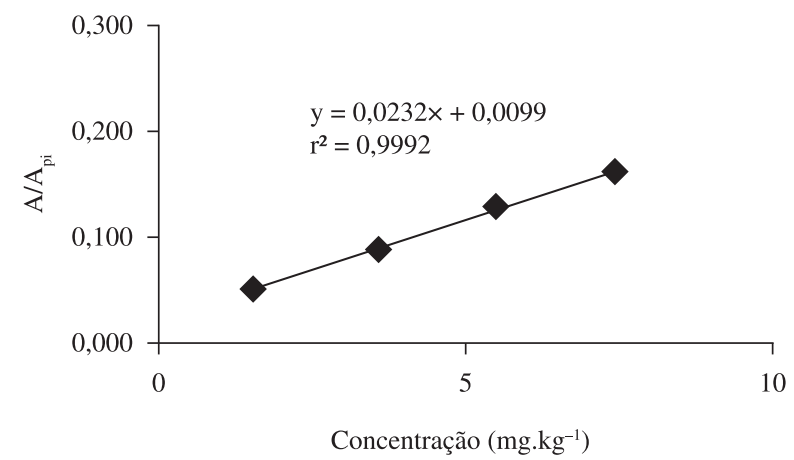

Figura 2. Curvas obtidas para o simulante aquoso para determinar os limites de detecção e de quantificação do método.
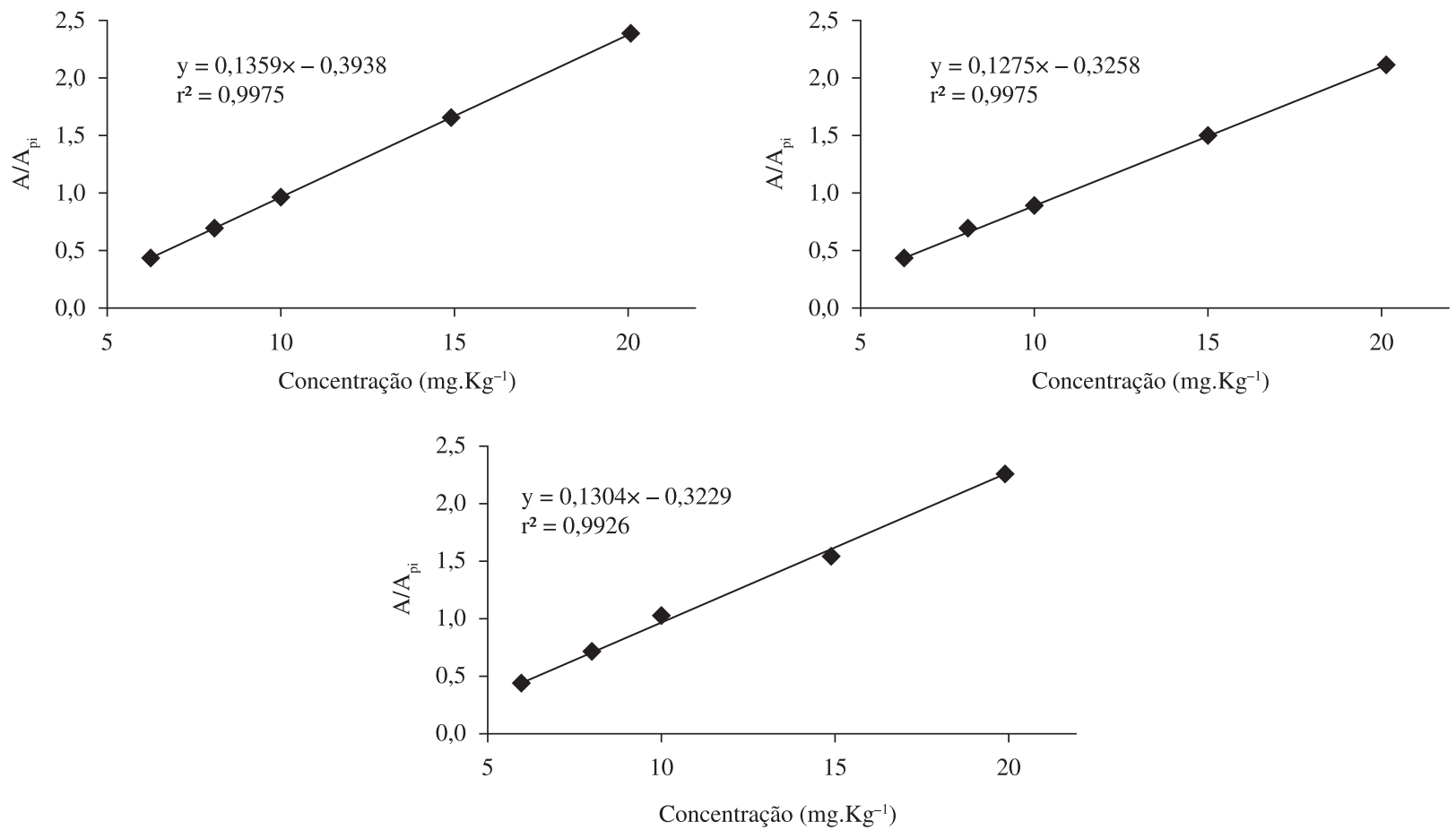

Figura 3. Curvas obtidas para o simulante ácido para determinar os limites de detecção e de quantificação do método. 

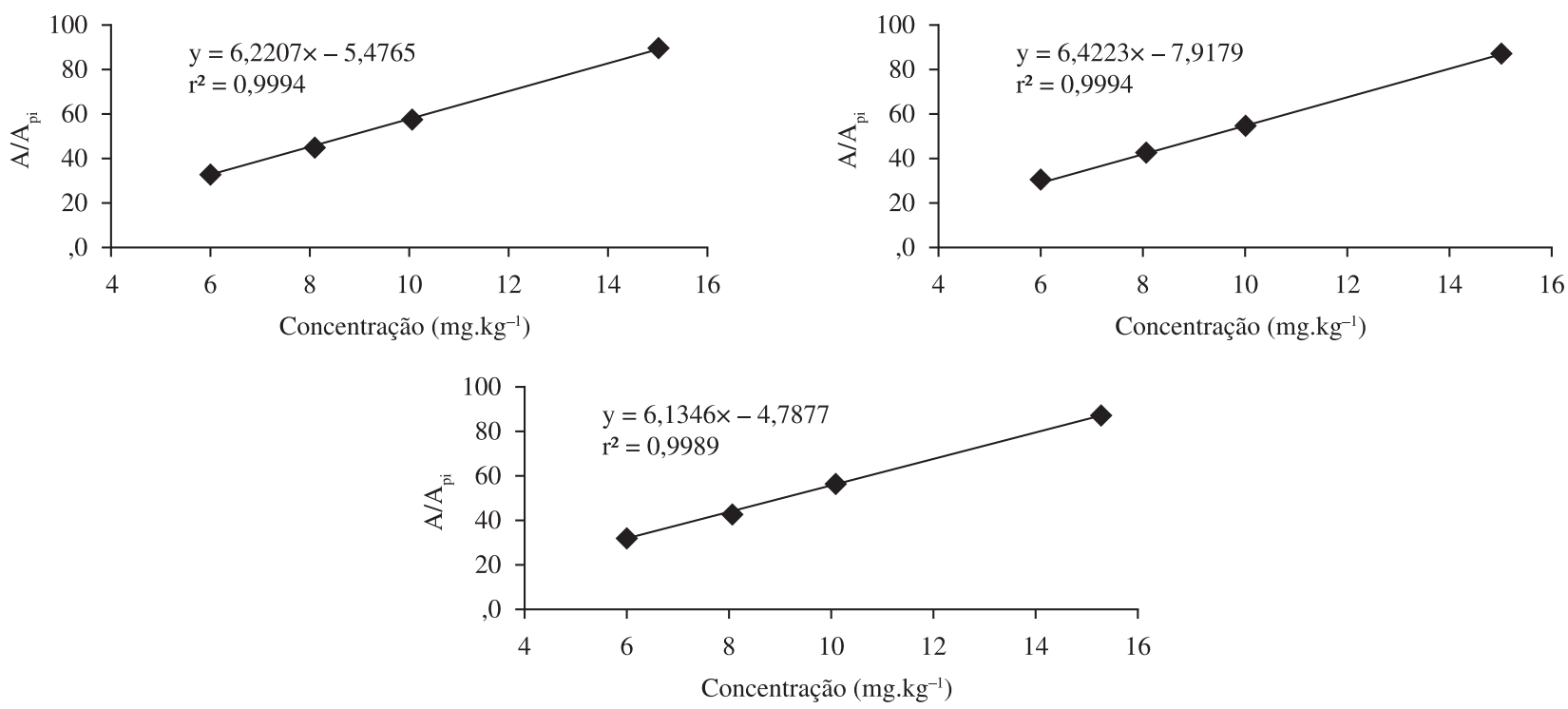

Figura 4. Curvas obtidas para o simulante gorduroso para determinar os limites de detecção e de quantificação do método.

Tabela 4. Precisão e exatidão do método.

\begin{tabular}{cccc}
\hline Simulantes & $\begin{array}{c}\text { Precisão } \\
\text { intracorrridas } \\
(\boldsymbol{\%})\end{array}$ & $\begin{array}{c}\text { Precisão } \\
\text { intercorridas } \\
(\boldsymbol{\%})\end{array}$ & $\begin{array}{c}\text { Exatidão } \\
(\boldsymbol{\%})\end{array}$ \\
\hline Aquoso & $1-4$ & $4-5$ & $99-105$ \\
Ácido & $1-2$ & $1-4$ & $97-105$ \\
Gorduroso & $0-2$ & $1-4$ & $98-105$ \\
\hline
\end{tabular}

ANVISA ${ }^{[20]}$, conclui-se que há repetibilidade e reprodutibilidade no método estudado. Os valores de exatidão obtidos também são adequados, pois apresentaram variação máxima de $5 \%$ em relação ao valor teórico $(100 \%)$, garantindo eficiência e validando o método.

Os resultados obtidos apresentaram valores superiores àqueles obtidos por Dopico-Garcia, López-Vilarino e GonzálezRodriguez ${ }^{[15]}$, os quais obtiveram $78 \%$ de exatidão e precisão de 6,5\% para a determinação da migração específica de Irganox 1076 para os simulantes aquosos ácido e alcoólico empregando extração em fase sólida com cartucho de sílica $\mathrm{C}_{18}$ e determinação por cromatografia líquida de alta eficiência com detector de arranjo de diodos. Os mesmos autores obtiveram $71 \%$ de exatidão e precisão de $13 \%$ para a determinação da migração específica de Irganox 1076 para o simulante aquoso empregando extração líquido-líquido e determinação por cromatografia líquida de alta eficiência com detector de arranjo de diodos ${ }^{[11]}$.

\section{- Limite de detecção e limite de quantificação}

As curvas obtidas para cada simulante são apresentadas nas Figuras 2-4. A partir destas curvas foram calculados o limite de detecção e o limite de quantificação para cada simulante, cujos resultados são apresentados na Tabela 5 .

Os limites de detecção e de quantificação obtidos pelo método analítico proposto foram maiores do que os valores obtidos por Dopico-Garcia, López-Vilarino e González-Rodriguez ${ }^{[15]}$, os quais obtiveram limite de detecção de $0,06 \mathrm{mg} \cdot \mathrm{L}^{-1}$ e limite de quantificação de $0,20 \mathrm{mg} \cdot \mathrm{L}^{-1}$ para a determinação da migração específica de Irganox 1076 para os simulantes aquosos ácido e alcoólico empregando extração em fase sólida com cartucho de sílica $\mathrm{C}_{18}$ e determinação por cromatografia líquida de alta eficiência com detector de arranjo de diodos.
Tabela 5. Limite de detecção e limite de quantificação para os diversos simulantes.

\begin{tabular}{ccc}
\hline Simulantes & $\begin{array}{c}\text { Limite de detecção } \\
\left(\mathbf{m g . k g}^{-1}\right)\end{array}$ & $\begin{array}{c}\text { Limite de quantificação } \\
\left(\mathbf{m g . k g}^{-1}\right)\end{array}$ \\
\hline Aquoso & 0,38 & 1,28 \\
Ácido & 0,92 & 3,06 \\
Gorduroso & 0,79 & 2,63 \\
\hline
\end{tabular}

No entanto, o método proposto permite a quantificação da migração específica do Irganox 1076 de embalagens plásticas para contato com alimentos aquosos, ácidos e gordurosos, uma vez que o limite de quantificação é inferior ao limite de migração específica do aditivo estabelecido pela ANVISA ( $\mathrm{LME}=6,0 \mathrm{mg} \cdot \mathrm{kg}^{-1}$ ).

Portanto, os resultados de validação obtidos para os simulantes aquoso, ácido e gorduroso mostraram-se satisfatórios para a implantação do método de avaliação da migração específica do Irganox 1076 de embalagens plásticas.

\section{Determinação da migração específica de amostras de filmes plásticos}

Nas análises cromatográficas dos simulantes aquoso e ácido que ficaram em contato com as amostras de filmes plásticos não foi observada a presença do pico referente ao Irganox 1076, indicando que não houve migração desse aditivo para estes simulantes ou que a migração está abaixo do limite de detecção do método (Tabela 5), atendendo assim o requisito de LME da ANVISA para este aditivo.

A Figura 5 apresenta os cromatogramas referentes ao simulante gorduroso (isooctano) que ficou em contato com as amostras de filme de PEBD e de EVA para avaliação do potencial de migração do Irganox 1076 para este simulante de alimento.

Os resultados obtidos para o filme de PEBD mostraram que a migração do Irganox 1076 para o simulante gorduroso foi inferior a $6 \mathrm{mg} \cdot \mathrm{kg}^{-1}$, atendendo ao requisito de LME da ANVISA. Porém, não foi possível determinar a concentração de Irganox 1076 que migrou para o simulante, uma vez que o valor era inferior ao limite de quantificação do método.

Os resultados obtidos para o filme de EVA mostraram que a concentração média do Irganox 1076 que migrou para o simulante gorduroso foi igual a 5,7 $\pm 0,1 \mathrm{mg} \cdot \mathrm{kg}^{-1}$. Essa concentração é inferior ao LME do Irganox 1076 estabelecido pela ANVISA e, portanto, este filme atende ao requisito estabelecido. 


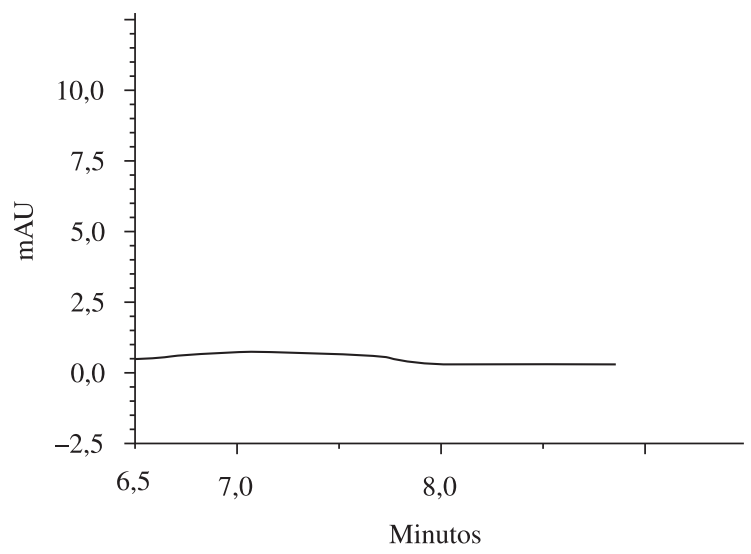

(a)

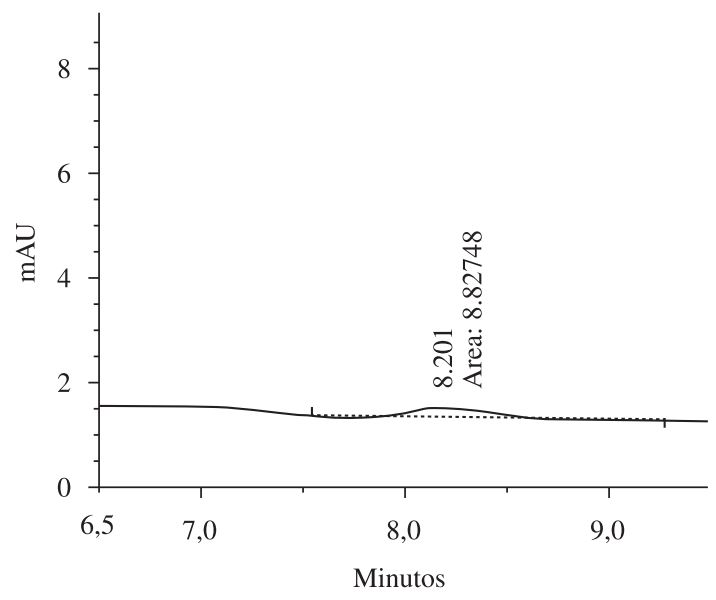

(b)

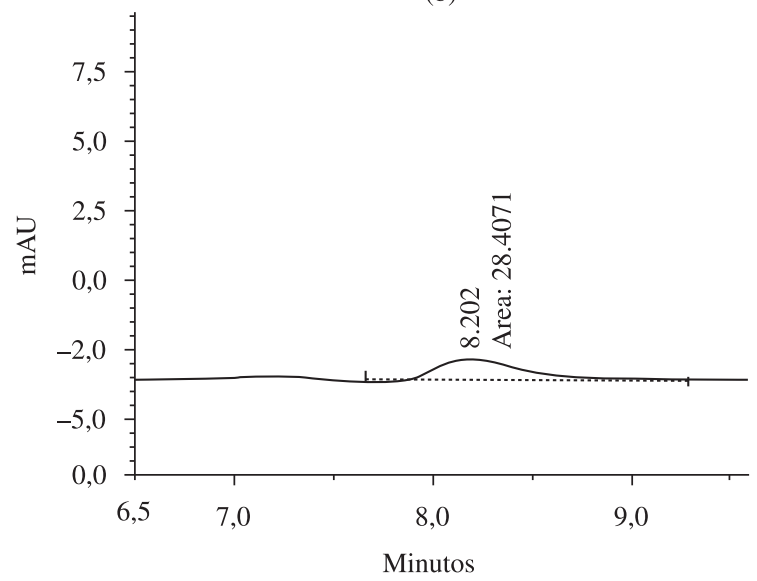

(c)

Figura 5. Cromatogramas referentes ao simulante gorduroso que ficou em contato com: a) branco (isooctano), b) filme de PEBD, e c) filme de EVA.

\section{Conclusões}

Os resultados obtidos indicam que a metodologia utilizada para a análise da migração específica do Irganox 1076 para os simulantes aquoso, ácido e gorduroso é adequada, uma vez que todos os parâmetros necessários para a validação do método foram atingidos.

O método cromatográfico utilizado tem a vantagem de ser simples e empregar eluição isocrática, permitindo análise mais rápida do que o método de gradiente e com menor consumo de reagente.
Os limites de detecção e de quantificação do método foram inferiores ao limite de migração específica do aditivo $\left(6 \mathrm{mg} \cdot \mathrm{kg}^{-1}\right)$, indicando que é possível quantificar uma possível migração do Irganox 1076 de embalagens plásticas para o alimento dentro do limite estabelecido pela ANVISA.

A precisão e exatidão do método permitem concluir que o mesmo apresenta boa repetibilidade e reprodutibilidade, além de elevada taxa de recuperação.

Sob o aspecto da migração específica do Irganox 1076, as amostras de filme de EVA e de PEBD analisadas não apresentam restrição de uso para contato com alimentos e bebidas do tipo aquoso, ácido e gorduroso, para acondicionamento e uso prolongado, a temperaturas de até $40{ }^{\circ} \mathrm{C}$.

\section{Agradecimentos}

As autoras agradecem ao $\mathrm{CNPq}$ pela bolsa concedida, à Ciba Especialidades Químicas Brasil e à Petroquímica Triunfo S/A pela doação dos padrões de aditivos e das amostras de filmes plásticos (EVA e PEBD).

\section{Referências Bibliográficas}

1. Sarantópoulos, C. - "Embalagens Plásticas Flexíveis: Principais Polímeros e Avaliação de Propriedades", ITAL/CETEA, Campinas (2002).

2. Rabello, M. - "Aditivação de Polímeros", Artliber, São Paulo (2000).

3. Schwarzenbach, K.; Gilg, B.; Müller, D.; Knobloch, G.; Pauquet, J.-R.; Rota-Graziosi, P.; Schmitter, A.; Zingg, J. - "Antioxidants", in: Plastics Additives, Handbook, cap.1, H. Zweifel (ed.), Hanser Publishers, Munich (2001).

4. Coltro, L.; Buratin, A. E. P. - Polímeros, 14, p.206 (2004).

5. Wang, F. C.-Y. - J. Chromatogr. A, 891, p.325 (2000).

6. Agência Nacional de Vigilância Sanitária - ANVISA. - "Resolução n. 17, de 17 de março de 2008. Dispõe sobre regulamento técnico sobre lista positiva de aditivos para materiais plásticos destinados à elaboração de embalagens e equipamentos em contato com alimentos". Diário Oficial União, Brasília, 18 mar. (2008). Sec. I. p. 43-51.

7. Nerin, C. - "Migración en poliolefinas", in: Migración de Componentes y Residuos de Envases en Contacto con Alimentos, cap. 11,p. 205-218, R. Catalá y R. Gavara (ed.), Valencia (2002).

8. García, R. S. - "Estudio de la Migración de Distintos Componentes de los Materiales Plásticos a los Alimentos", Tese de Doutorado, Universidade de Santiago de Compostela, Espanha (2005).

9. Simoneau, C.; Hannaert, P. - Food Addit. Contam., 16, p.197 (1999).

10. O’Brien, A. P.; Cooper, I.; Tice, P. A. - Food Addit. Contam., 14, p.705 (1997).

11. Dopico-Garcia, M. S.; Lopez-Vilarino, J. M.; Gonzalez-Rodriguez, M. V. - J. Chromatogr. A, 1018, p.53 (2003).

12. Jeon, D. H; Park, G. Y.; Kwak, I. S.; Lee, K. H.; Park, H. J. - Food Sci. and Techn., 40, p.151 (2007).

13. Marcato, B.; Guerra, S.; Vianello, M.; Scalia, S. - Intern. J. Pharmac., 257, p.217 (2003).

14. Lundbäck, M.; Hedenqvist, M. S.; Mattozzi, A.; Gedde, U. W. - Polym. Degr. and Stab. 91, p.1571 (2006).

15. Dopico-García, M. S.; López-Vilariño, J. M.; González-Rodríguez, M. V. - Talanta, 66, p.1103 (2005).

16. Sanches Silva, A.; Sendón García, R.; Cooper, I.; Franz, R.; Paseiro Losada, P. - Trends in Food Sci. \& Techn., 17, p.535 (2006).

17. Bertoldo, M.; Ciardelli, F. - Polymer, 45, p.8751 (2004). 
18. Sanches Silva, A.; Cruz, J. M.; Sendón Garcıa, R.; Franz, R.; Paseiro Losada, P. - Meat Sci., 77, p. 238 (2007).

19. American Society for Testing and Materials - ASTM. "D6953-03: Standard test method for determination of antioxidants and erucamide slip additives in polyethylene using liquid chromatography (LC)", ASTM International, Philadelphia (2009).

20. Agência Nacional De Vigilância Sanitária - ANVISA. - "Resolução n. 899, de 29 de maio de 2003. Guia para Validação de Métodos Analíticos e Bioanalíticos". Diário Oficial União, Brasília, 2 jul. (2003).

21. Instituto Nacional de Metrologia, Normalização e Qualidade Industrial - INMETRO. - "Orientações sobre validação de métodos de ensaios químicos”. DOQ-CGCRE-008, Rio de Janeiro, 2003. Revisão 02, 25p.

22. European Commitee for Standardization - ECS. - "CEN/TS 13130-16: Materials and articles in contact with foodstuffs - Plastics substances subject to limitation - Part 16: Determination of caprolactam and caprolactam salt in food simulants", ECS (2005). 15p.
23. Agência Nacional de Vigilância Sanitária - ANVISA. - "Resolução RDC n. 51, de 26 de novembro de 2010. Dispõe sobre migração em materiais, embalagens e equipamentos plásticos destinados a entrar em contato com alimentos”. Diário Oficial da União, Brasília, 22 dez. (2010). Sec. I. p. 75-79.

24. European Commitee for Standardization - ECS. - "EN 13130-1:2004: Materials and articles in contact with foodstuffs - Plastics substances subject to limitation - Part 1: Guide to the test methods for the specific migration of substances from plastics to food and food simulants and the determination of substances in plastic and the selection of conditions of exposure to food simulants)", ECS (2004). p. 1-65.

Enviado: 05/02/10

Reenviado: $15 / 09 / 10$

Aceito: 04/05/11

DOI: $10.1590 / \mathrm{S} 0104-14282011005000064$ 